\title{
Systematic review as a research method in post- graduate nursing education
}

\author{
Wilma ten Ham-Baloyi", Portia Jordan \\ Nelson Mandela Metropolitan University, Department of Nursing Science, Port Elizabeth, South Africa
}

\section{A R T I C L E I N F O}

Article history:

Received 5 February 2015

Accepted 20 August 2015

Available online 1 October 2015

Keywords:

Critical interpretive synthesis

Methodology

Post-graduate nursing education

Research

Systematic review

\begin{abstract}
A B S T R A C T
In South Africa, there appears to be poor understanding about using a systematic review as an acceptable research method in post-graduate nursing education. The lack of understanding may result in research supervisors being unable to guide post-graduate students, such as masters and doctoral students, in using the systematic review methodology in the completion of an academic qualification. Furthermore, they might not be able to assist post-graduate students in completing their studies, or conducting studies, in particular systematic reviews, which are of high quality. Valuable opportunities can thus be missed that might add to the body of knowledge to inform and improve research, education, and clinical practice. This article may set the field for an informed debate on systematic reviews as a useful and acceptable research method to be used by post-graduate nursing students in South Africa. We conclude that a systematic review could be a useful and acceptable method for research in post-graduate nursing education. However, the method's benefits and disadvantages should be considered before a post-graduate student embarks on such a journey.

(c) 2015 The Authors. Publishing services by Elsevier B.V. on behalf of Johannesburg University. This is an open access article under the CC BY-NC-ND license (http://

creativecommons.org/licenses/by-nc-nd/4.0/).
\end{abstract}

\section{Contents}

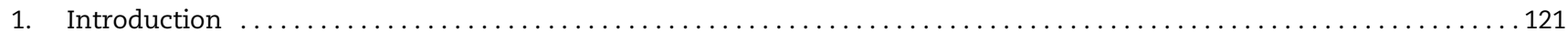

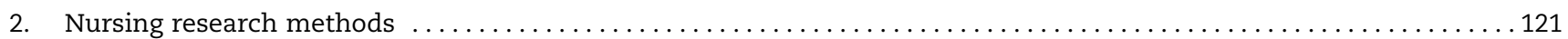

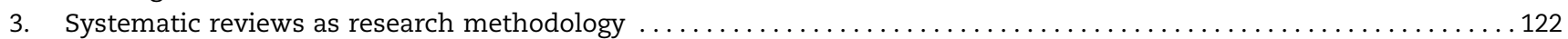

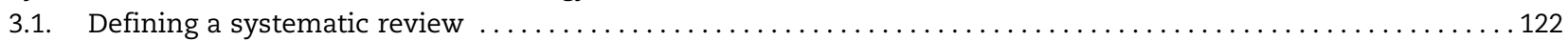

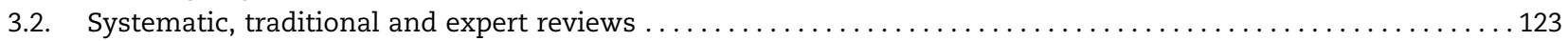

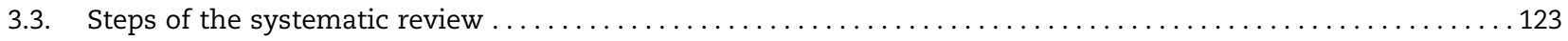

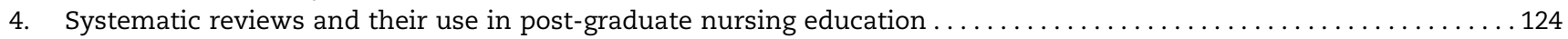

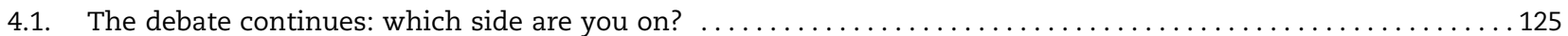

4.2. Advantages and disadvantages of doing a systematic review at postgraduate level $\ldots \ldots \ldots \ldots \ldots \ldots \ldots \ldots$

4.3. Criteria for postgraduate nursing students who wish to undertake a systematic review $\ldots \ldots \ldots \ldots \ldots \ldots$

\footnotetext{
* Corresponding author. Tel.: +27 (0)41 504 2959; fax: +27 (0)41 5042616.

E-mail address: wilma.tenham-baloyi@nmmu.ac.za (W. ten Ham-Baloyi).

Peer review under responsibility of Johannesburg University.

http://dx.doi.org/10.1016/j.hsag.2015.08.002

1025-9848/@ 2015 The Authors. Publishing services by Elsevier B.V. on behalf of Johannesburg University. This is an open access article under the CC BY-NC-ND license (http://creativecommons.org/licenses/by-nc-nd/4.0/).
} 


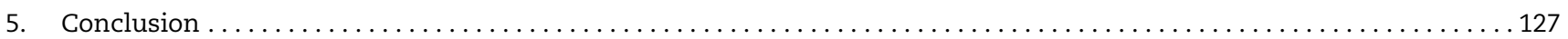

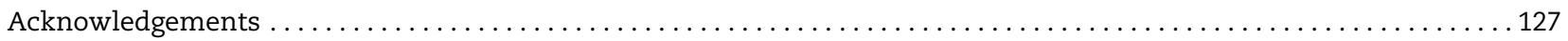

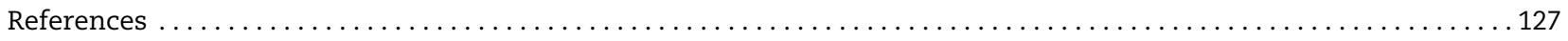

\section{Introduction}

A 'systematic review' refers to a literature review associated with a clearly formulated research question that uses systematic explicit methods to identify, select, and critically appraise relevant research from previously published studies related to the question at hand (The Cochrane Collaboration, 2005). The systematic review process employs literature review methods to select only those studies that meet specific criteria which reasonably confirm the rigour of the 'evidence' produced by a previously published study. The primary characteristic of a systematic review is that it uses a rigorous set of criteria by which to appraise the reliability and validity of previously published research.

Systematic reviews are increasingly being used as a preferred research method for the education of post-graduate nursing students (Bettany-Saltikov, 2012; Sambunjak \& Puljak, 2010) as these reviews provide a mechanism for identifying the most robust evidence-based research from among the range of research studies being published (Lam \& Kennedy, 2005). As a result, a systematic review plays an increasingly important role in formulating evidence-based nursing practice by including only the highest quality evidence for the development of best-practice guidelines, and to better direct nursing practice (Dixon-Woods et al., 2006; Scott et al., 2007).

A strong international community of discourse currently exists regarding the use of systematic reviews as a research method for master nursing students and this method is increasingly being used as an acceptable method for clinical doctorate students owing to its evidence-based nature, and its results being relevant for clinical practice (Kung et al., 2010). Publishing a systematic review or conducting a high-quality integrative literature review as part of a doctoral is, however, not yet accepted (Olsson, Ringnér, \& Borglin, 2014; Sambunjak \& Puljak, 2010) as the doctoral degree holds expectation of knowledge discovery, but not necessarily synthesis and application of knowledge.

Globally, ensuring high quality of post-graduate nursing education is the priority of many organisations. For example, one of the aims of the International Network for Doctoral Education in Nursing (INGEN) is to enhance doctoral education by promoting networking between doctoral educators to address issues of shared interest globally (The Johns Hopkins University School of Nursing, 2015, and the Sigma Theta Tau International has a centre for excellence in nursing education, including post-graduate nursing education (Sigma Theta Tau International, 2015). In South Africa, clear post-graduate requirements exist, and the need to generate an increased number of masters and doctorates as well as postgraduate research supervision, increases. The Academy of Science in South Africa (ASSAF) concurs in stating that a quality $\mathrm{PhD}$ should enhance the student's systematic understanding of the field of study as well as the research methods associated with the field, have made a contribution through original research, and should be able to critically analyse, evaluate and synthesise complex ideas (ASSAF, 2010). This is in line with the National Qualification Framework (NQF)'s level descriptors for Masters (NQF level 9) and PhD (NQF level 10), which outlines the abilities of problem solving, in-depth knowledge about the topic researched, and the research method (South African Qualifications Authority, 2012). A systematic review could be a good research method to be used for post-graduate education because it not only enhances problem solving by using critical and analytical thinking and acquiring in-depth knowledge of a variety of research methods, but it can provide opportunities for networking by contacting different authors of publications nationally and globally (Sambunjak \& Puljak, 2010). A systematic review is a cost-effective research method which does not require a lengthy ethical approval process, and may generate more high-quality masters and doctoral graduates who will fulfil the need for postgraduate education and supervision (Academy of Science in South Africa, 2010). However, in South Africa there is little understanding of the systematic review process and its scientific rigour as a research method in post-graduate nursing education. There exists only a limited research community of nurse educators who share a common understanding of systematic review methods, who can act as post-graduate research supervisors and mentors (Boland, Cherry, \& Dickson, 2008). Because of this limited availability, missed opportunities prevail for adding to the body of evidence-based nursing science and practice, including the development of robust nursing practice clinical guidelines to inform clinical practice, which is fundamentally based on a systematic review (Hemington \& Brereton, 2009).

As a result of the relative newness of the systematic review process in post-graduate nursing education in South Africa, there exists a paucity of information and clear understandable guidelines to produce a rigorous systematic review. This article aims to provide a clear roadmap for conducting a systematic review, as well as discussing its potential and limitations for use by post-graduate nursing students. 'Postgraduate nursing students' in this context refers to masters and doctoral students who conduct research at an academic institution towards obtaining an academic qualification. Cognisance is taken of a clinical doctorate, but in South Africa, obtaining clinical doctorates is not general practice.

\section{Nursing research methods}

Nursing research dates as far back as the 1850s when Florence Nightingale identified problems in nursing practice and began to produce a systematic collection of data to address these problems (Cantelon, 2010; Moule \& Goodman, 2009). 
In traditional nursing research, which is grouped among other social science research disciplines, opinions and beliefs about phenomena are referred to as 'statements'. Each statement holds a knowledge claim which is linked to a specific reality (Mouton \& Marais, 1990). When critically examining these statements, one could question the objective basis on which they were made (Hancock, 2002; Mouton \& Marais, 1990). Different approaches have been used to validate the truth in such statements, for example, personal preferences and feelings, authoritative position, and casual observation (Burns \& Grove, 2013; Mouton \& Marais, 1990:5-6). However validation is attempted, these methods remain subjective, and subject to change based on idiosyncratic factors. As a result, the need has arisen for more rigorous research methods defined as "process[es] that involve obtaining scientific knowledge by means of various objective methods and procedures" (Welman, Kruger, \& Mitchell, 2012).

In nursing research, qualitative research methods have long been used as the preferred model for social and behavioural science enquiry (Lincoln \& Guba, 1985). According to Holloway and Fulbrook (2001), qualitative research is the preferred research method for nurses and midwives because it is a "human-centred"' and holistic approach that is consistent with the philosophical underpinnings of the nursing profession. In the past twenty years, practice and evidencebased clinical decision-making has become a central tenet that guides clinical practice in healthcare institutions and frames the design of health services research (Sackett, Strauss, Richardson, Rosenberg, \& Haynes, 2000:1).

The concept of evidence-based practice has increased the awareness to use various pieces of evidence and/or research, other than only using qualitative or quantitative research paradigms. Researchers are increasingly using evidence from previously conducted studies to inform their own research question (the 'why' of the statement). Evidence can be ranked according to the hierarchy of evidence (Fig. 1), where different types of evidence are recognised. Systematic reviews and meta analyses in studies using randomised controlled trials

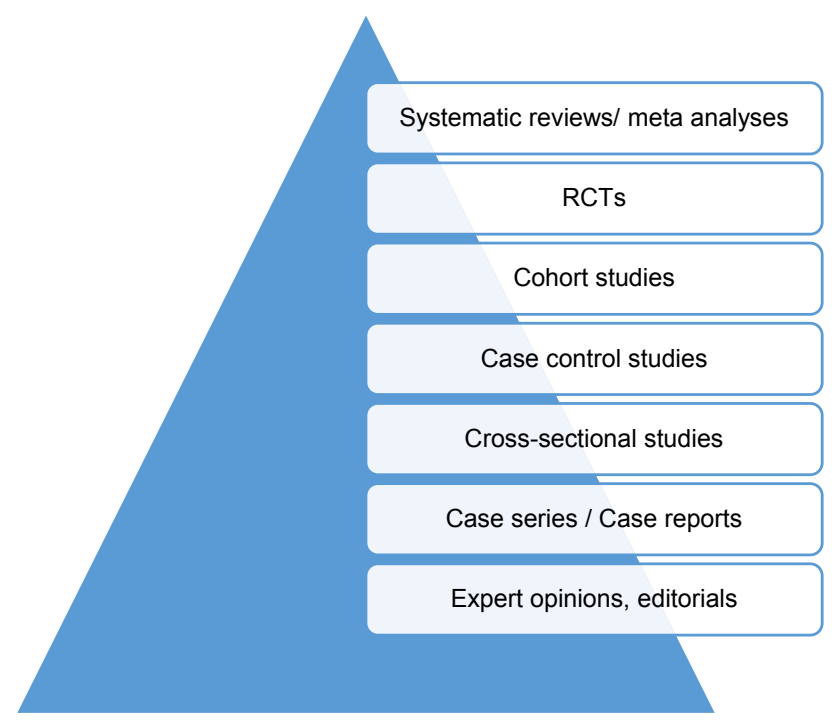

Fig. 1 - The hierarchy of evidence (adapted from: Evans, 2003).
(RCTs) are considered superior in the hierarchy of evidencebased research, while qualitative case studies and expert opinions occupy the lowest rung on this hierarchical ladder (Evans, 2003; Frymark et al., 2009).

It should be noted that an RCT deemed to have strong internal validity (established a statistically significant causal link between intervention and outcome) may have weak external validity (its applicability across settings and populations) when compared to descriptive studies (Evans, 2003; Melnyk, 2004). Inherent in this rating hierarchy is the belief that systematic literature reviews produce the highest level of evidence (LoBiondo \& Haber, 2010). The preference to include the so-called high ranking types of studies on the hierarchy of evidence in systematic reviews is evident. Systematic reviews increasingly include a component of meta-analysis, which refers to using statistical techniques to synthesise the data from included studies into a "quantitative estimate" or "summary effect size" (Petticrew \& Roberts, 2006). However, this is only applicable when quantitative studies are included in the review. When including qualitative studies, a qualitative approach to synthesise the extracted data may be more applicable (Thomas \& Harden, 2007).

While the conduct of original research is essential for producing new data, insights, and evidence, the protocols associated with the systematic review process informs the researcher about what is known, how the evidence was produced, and how it may vary across studies based on study populations and contextual factors (Kitchenham, 2004).

Considering the historical background to nursing research, the hierarchy of evidence and the need for the inclusion of high-quality research to inform education, research and practice, a paradigm shift is required to use a diversity of research paradigms, including systematic reviews. An increased awareness of the systematic reviews to inform education, research and practice is evident among researchers.

\section{Systematic reviews as research methodology}

In order to understand systematic reviews as a research methodology, a definition, followed by the steps to follow when conducting a systematic review, is provided.

\subsection{Defining a systematic review}

A systematic review is defined as "[a] review of a clearly formulated question that uses systematic and explicit methods to identify, select, and critically appraise relevant research, and to collect and analyse data from the studies that are included in the review. Statistical methods (meta-analysis) may or may not be used to analyse and summarise the results of the included studies" (The Cochrane Collaboration, 2005).

According to Gough, Oliver, and Thomas (2012), a systematic review is a research method that is undertaken to review research literature, using systematic and rigorous methods. Systematic reviews are often referred to as 'original empirical research' because they review primary data, which can be 
either quantitative or qualitative (Aveyard \& Sharp, 2011). Systematic reviews can be considered as the 'gold standard' for reviewing the extant literature on a specific topic as it synthesises the findings of previous research investigating the same or similar questions (Boland et al., 2008).

\subsection{Systematic, traditional and expert reviews}

According to Gough et al. (2012), systematic reviews employ explicit, rigorous, and accountable methods to inform new research questions. Reviewing research systematically involves three key activities: identifying and describing previously published relevant research; critically appraising the research methods, and bringing together the aggregated findings into a synthesis of research findings. Systematic reviews are more rigorous than a traditional literature review because they use a systematic approach to search, select, and appraise the produced evidence.

A traditional literature review often presents a summary of published research related to a topic of interest without a sorting based on the quality or rigour of the study design and methods identified. It summarises all published studies on the topic, and leaves it to the reviewer to determine the study's quality on a study-by-study basis. The traditional literature review uses often unsystematic and objective methods, and is not based on rigorous criteria and tools such as a systematic search strategy, algorithms to critically appraise identified articles, and systematic methods to analyse and synthesise the data, and therefore it is not possible to assess the quality or rigour of the methods of the included studies. A traditional review is therefore more prone to bias than a systematic review, including selection bias, when only studies which are published are selected, and language bias, when studies are selected based on their language of publication, such as English (Aveyard \& Sharp, 2011; Gough et al., 2012).

There may be great insight and knowledge transferred in both a traditional review and a systematic review, but the lack of transparency about the traditional review process methods calls its findings into question. Expert reviews often lack: perspective and conceptual framework, inclusion criteria for evidence, nature of search for evidence, quality and relevant appraisal of the evidence, and method of synthesis of the evidence, methods which are typically considered when performing a systematic review (Evidence for Policy and Practice, 2010; Gough et al., 2012).

Traditional literature reviews are all too often restricted to literature already known to the authors, or literature that is found by conducting little more than cursory searches. This means that the same studies are frequently cited, and this introduces a persistent bias to literature reviews. Systematic reviews help reduce implicit researcher bias through the adoption of broad search strategies, predefined search strings, and uniform inclusion and exclusion criteria; systematic reviews effectively force researchers to search for studies beyond their own subject areas and networks (Mallett, HagenZanker, Slater, \& Duvendack, 2012).

The steps of the systematic review are discussed next.

\subsection{Steps of the systematic review}

Researchers differ on the number of steps taken when conducting a systematic review. However, the sequence of the steps is similar. Systematic reviews should be carried out prospectively and comprehensively, using an explicit algorithm that specifies the protocols that are guiding the research, for a well-defined research question or questions. The steps of systematic review are structured and well-defined and various frameworks, for instance the Cochrane Collaboration, Joanna Briggs Institute, can be used to guide the systematic review process. When conducting an integrative literature review, a structured framework, for instance one indicated by Whittemore and Knafl (2005) can be used to guide the process. The five steps of the systematic review are discussed below.

Step 1: Review question - The question(s) that are to guide the systematic review must be answerable and searchable and therefore should include the following variables: population of interest (P), intervention (I), comparative interventions $(\mathrm{C})$ and the outcomes of interest $(\mathrm{O})$ known as the PICO format (The Cochrane Collaboration, 2005). Alternatively, PICOT (to assess effect and timeframe) (Melnyk \& Fineout-Overholt, 2005) or PICOC (to assess the context) can be used (The Cochrane Collaboration, 2005). The PICO, PICOT or PICOC methods help to specify the right question(s), which is a requirement for finding robust studies to produce valid and reliable results. Depending on the purpose of the review, the reviewer can either choose the PICO, PICOT or PICOC format. During the review question formulation process, these methods assists in identifying the subsequent search words for the literature review. Systematic reviews are often registered with systematic review research networks, for instance, the Cochrane Collaboration (medicine) or the Campbell Collaboration (education and law-related reviews) or the Joanna Briggs Institute. The aims of register reviews are to reduce bias of the review, to reduce duplication, to keep systematic reviews updated (The PLoS Medicine Editors, 2011) and to provide a library with all systematic reviews related to a specific profession. For the purpose of post-graduate nursing studies, registering of the systematic review with a network is optional (Mallett et al. 2012).

Step 2: Searching the literature - This step involves the formulation of a search strategy, which includes inclusion and exclusion criteria, keywords, sources of evidence, the documentation of the search, and selection of the research reports to be included. Librarians can play a crucial role in many stages of a systematic review, especially when searching the literature. Their roles are multiple and involve applying their knowledge based on experience and training and their abilities to develop search strategies, including the choice of keywords and databases (McGowan \& Sampson, 2005) but are not limited to organising of data and analysing of data to be included in the search (Harris, 2005). A librarian should therefore be involved to help with expanding the search, ensuring a comprehensive search which increases the robustness of the entire study (Kitchenham, 2004). The selection of relevant articles is based on two concepts: sensitivity and specificity. To ensure sensitivity, the total number of studies that meet the inclusion criteria of the search 
strategy should be recorded, although some will later be discarded owing to a lack of relevancy. To ensure specificity, nonrelevant studies should be excluded in the next phase. The relevance of some studies can be determined from the title (and abstract if available) but in other cases the decision can only be made after the full text article has been reviewed. Throughout the search, all studies reviewed should be recorded (Centre for Evidence-Based Conservation, 2009; Centre for Review and Dissemination, 2009).

Step 3: Critical appraisal - The next step is an in-depth appraisal of the selected studies so that reported research not meeting the inclusion criteria, including the strength of the evidence, can be excluded from the final sample (Centre for Evidence-Based Conservation, 2009). A variety of critical appraisal instruments could be used to appraise the studies in a systematic review. However, a disadvantage of critical appraisal instruments is that there is not one single tool that can be fully applied to all studies (CRD, 2009). Tools that could be used for different types of studies can include the following: AMSTAR tool for the 'assessment of multiple systematic reviews' (Shea et al., 2007) the evaluation tool for quantitative research studies (Health Care Practice Research and Development Unit, 2005) the MAStARI critical appraisal tools for randomised control or pseudo-randomised trial (Johanna Briggs Institute, 2011), Critical appraisal instrument for qualitative research studies (CASP, 2006), the John Hopkins nursing evidence-based practice (JHNEBP) or the research evidence appraisal tool (Newhouse, Dearholt, Poe, Pugh, \& White, 2007:210). As it is sometimes challenging to obtain information concerning the validity and reliability of most of the critical appraisal instruments, the decision regarding which critical appraisal instruments to use, was made based on the criterion that all instruments should fit the type of study used, as this strengthens its internal validity (Akobeng, 2005). The study appraisal criteria should be explicit and specified at the onset of the critical appraisal process, and ensure appropriateness for the research methods being reviewed (Centre for Reviews and Dissemination, 2009). An internally consistent review is achieved when two or more reviewers agree on the robustness of the study being reviewed, that is, when interrater reliability is high (Burns \& Grove, 2013). The critical appraisal process should be done by the researcher and an independent reviewer, using the selected appraisal tools. Once the critical appraisal process is completed, consensus should be reached between the researcher and the reviewer. A decision, based on the appraisal results should then be reached on the inclusion or exclusion of the appraised studies.

Step 4: Data extraction - According to the CRD (2009:28), data extraction is "the process by which researchers obtain the necessary information about study findings from the included studies." Data extraction is the step in which all relevant findings meeting the selection criteria are aggregated to form the body of evidence regarding the research question(s) posed. Various data extraction tools, for instance the Joanna Briggs Institute tools, are available to perform the data extraction.

Step 5: Data synthesis - Data synthesis is the stage in the review process when studies meeting inclusion criteria are summarised to form the outcome of the systematic review (Centre for Reviews and Dissemination, 2009; Kitchenham, 2004). The aims of the data synthesis are to aggregate study findings for all studies meeting the inclusion criteria; assess the strength of the study findings using agreed upon, specified assessment criteria; and to summarise the results in a systematic, evidence-based literature review document (Academy of Nutrition and Dietetics, 2012; Centre for Reviews and Dissemination, 2009). Syntheses can use various analytic frameworks, namely meta-ethnography, meta-analysis, thematic synthesis, or framework synthesis. The method used will depend on the types of evidence collected and appraised during the process. Depending on the heterogeneity or homogenous nature of the data extracted, the syntheses can be concluded and presented either thematically or on a forest plot or scatter diagram.

\section{Systematic reviews and their use in post- graduate nursing education}

To answer whether a systematic review can be used in postgraduate nursing education, the question of whether and how systematic reviews will make a substantive contribution to the body of clinical nursing knowledge must be answered. Is a systematic review a legitimate form of research? A current debate involves claims that a systematic review is too large and complex to constitute an individual masters or $\mathrm{PhD}$ level study. The sceptics argue that a rigorous systematic review should be conducted by a research team (Louw \& Keller, 2006). Furthermore it is debated that systematic reviews are not appropriate for qualitative studies. Another argument posits that systematic reviews should not be encouraged as they are not primary research, which involves conducting an original study including specifying a study design, collecting primary data, data analysis, and reporting findings. Finally, some academic naysayers argue that systematic reviews do not teach students the rigours of conducting a primary research project (Boland et al., 2008).

On the other hand, it can be argued that a systematic review involves the collection, analysis and interpretation of data, although the data derive from secondary sources (Kitchenham, 2004). However, some do not agree with this argument as postgraduate students undertaking systematic reviews use a systematic approach which is similar to the process of primary research (Hemington \& Brereton, 2009). This rigorous process is evident in the steps required by a systematic review previously discussed.

As in a primary research study, a systematic review requires that a clear research question be posed (Boland et al., 2008). As in primary research, the development of a rigorous proposal is a vital element of a systematic review. The systematic review proposal provides the plan by which the evidence-based review will be conducted and ensures the appropriate methodological rigour will be applied (Hemington \& Brereton, 2009). It should also be noted that the review proposal is developed in addition to the research proposal that is formally submitted to the research supervisor and institutional structures when doing it for a formal qualification or postgraduate nursing research.

In primary research, data is collected from the target population once a sampling plan has been devised and approved. However, in a systematic review, data from some 
number of previously conducted studies that have met a rigorous set of selection criteria is "collected" and analysed with reference to the specified research question(s) posed by the student researcher (Hemington \& Brereton, 2009; The Cochrane Collaboration, 2005).

A systematic review critically extracts and appraises data, which equates to data collection and analysis in primary research. In primary research, data synthesis, which is a comparable process to a systematic review, can employ either qualitative or quantitative data synthesis methods. In primary research, data is presented in the form of qualitative thematic statements or graphic presentation of quantitative data. In a systematic review, data is aggregated and presented as a meta-synthesis, meta-analysis, forest plots, or scatter diagrams, all of which are produced through a rigorous set of scientific protocols (Centre for Reviews and Dissemination, 2009; The Cochrane Collaboration, 2005).

Systematic reviews are regarded as a critical component of the development of evidence-based clinical practice; they support evidence-based practice based on clinical expertise and patient values (Sackett, Strauss, Richardson, Rosenberg, \& Haynes, 2000). The current need arises to develop additional evidence-based protocols beyond RCTs and case-control studies in the context of clinical nursing practice. We suggest that systematic reviews be conducted in non-traditional ways that push beyond the Cochrane systematic process, which is heavily biased towards RCTs, to find new ways to provide a more rigorous assessment of qualitative research studies (Hemington \& Brereton, 2009).

\subsection{The debate continues: which side are you on?}

Considering the different view presented, there is sufficient evidence to support systematic literature reviews as an approved research method in post-graduate nursing education and research, which will contribute to students' competencies in undertaking rigorous research in nursing (Olsson et al., 2014). At a masters degree level, students are expected to begin the process of engaging in critical thinking with regard to the research enterprise, including the ability to identify, conceptualise, design, and implement scientific enquiry that addresses complex and challenging clinical problems. On a $\mathrm{PhD}$ level, students are expected to make unique contributions to expanding the body of knowledge in clinical nursing in line with standards set by the National Qualifications Framework (NQF) of the South African Qualifications Authority (SAQA) (SAQA, 2012). At the graduate level, students are expected to engage in advanced meta-cognitive thought processes including abstract theorising, which only competencies in systematic reviews can offer (Khan, Kunz, Kleijnen, \& Antes, 2003). With this in mind, let us consider the advantages and disadvantages of doing a systematic review at postgraduate level.

\subsection{Advantages and disadvantages of doing a systematic review at postgraduate level}

Although systematic reviews have become a major area of methodological development and have created interest in the academic arena, it is essential to consider the advantages and disadvantages in relation to postgraduate nursing research. A list of the advantages and disadvantages, gathered from anecdotal evidence and the researcher's experiences, are listed in Table 1. Some of the advantages and disadvantages may be similar to those for master and PhD students conducting primary research, but these advantages and disadvantages are commonly observed by the researchers when students do systematic reviews.

\section{Table 1 - Advantages and disadvantages of systematic reviews in post-graduate nursing education.}

Advantages

- Use clear and thorough methods to identify and critcially appraise relevant studies in order to answer a well-defined research/review question.

- The post-graduate nursing student learns both systematic evidence-based review processes, as well as learning to use primary research methods

- Critical analysis skills are encouraged and can be mastered.

- Students learn new methods to do independent research.

- Systematic reviews provide an opportunity for nursing students to engage in a broader range of research methodologies.

- For Ph.D. students a more rigorous research foundation for their dissertation topic is established.

- No ethical approval is necessary due to its exclusive use of secondary data.

\section{Disadvantages}

- Time constraints as only a systematic review's search strategy may require 6 -8 months to complete, depending on the amount of relevant literature available and the search may even have to be updated to ensure no new data was published during the time of analysis and synthesis of the data.

- Capacity constraints in terms of faculty and staff supervisors skilled in systematic review methods.

- Infrastructural constraints if students do not have adequate access to electronic databases.

- Depending on the research question, a large or little amount of literature can constrict the literature review process.

- Assessment tools and tested algorithms may not be available for certain qualitative research methods.

- Systematic reviews are often difficult to publish in peer-reviewed journals. 
Table 2 - Criteria for undertaking a systematic evidence-based literature review.

The student must be able to demonstrate the following capabilities:

- Excellent record-keeping skills, as registering all research findings of studies meeting the inclusion criteria is essential for the success of a systematic review;

- Demonstrated ability for abstract thinking which is less practical than conducting other methods such as interviews;

- High computer literacy levels;

- Appropriate literature searching skills;

- Critical appraisal skills;

- An understanding of the diverse research methodologies that can be used in selected studies;

- Should preferably have access to a variety of databases (resources), otherwise inter-library loan services have to be used, which can be costly and time- consuming;

- Access to experts and the ability to collaborate with experts like librarians, independent reviewers and statisticians (in the case of a quantitative systematic review).

Similar advantages and disadvantages have been noted in the literature. Advantages such as students learning to develop a well-defined review question was mentioned by Olsson et al. (2014) who indicated the advantages of using a systematic review to refine and enhance a research question. Development of critical appraisal skills was mentioned by Hemington and Brereton (2009) who noted that critical appraisal skills are not difficult to develop as they use common-sense thought processes. Researchers at King's College London found that systematic reviews provide a planning function in the interpretation of new research results (2014). Systematic reviews can identify where evidence is lacking on a certain topic and thus make recommendations for closing the knowledge gap.

Disadvantages such as time and capacity contraints were confirmed by Bhavsar and Waddington (2015) who indicated that conducting a systematic review is time-consuming, complex, and process-orientated. The inability to publish systematic reviews in preferred journals was confirmed by Olsson et al. (2014). They stated that a lack of published systematic reviews may be due to the general view that a systematic review is 'less worthy' research for $\mathrm{PhD}$ students than studies based on primary data collection methods. However, PhD students can benefit from conducting and publishing a systematic review as part of their doctoral studies, which can be incorporated as a phase within the doctoral studies. Conducting a systematic review, as part of the bigger study, can give $\mathrm{PhD}$ candidates the opportunity to engage in a variety of methodologies and content of primary studies. They will also learn to solve problems by using critical and analytical thinking, and this is considered as a well-sought-after skill required for future researchers (Sambunjak \& Puljak, 2010). Furthermore, by using the results of the systematic review to develop interventions which can be implemented (Mallett et al. 2012) the student can make a unique and significant contribution to the field of nursing.

\subsection{Criteria for postgraduate nursing students who wish to undertake a systematic review}

Post-graduate nursing students wishing to conduct a systematic literature review will need to adhere to specific protocols and inclusion criteria in order to conduct an acceptable, rigorous, and robust systematic review. These criteria are listed in Table 2.

Both the disadvantages and advantages and the criteria for conducting a systematic review should be considered before even commencing a systematic review. For example, one should consider whether the educational institution is able to provide the resources such as accessible electronic databases to conduct a comprehensive search, a librarian with experience with literature search strategies. The budget for the review should also be considered with regard to the independent reviewer, the librarian and eventually a statistician. Educational institutions should be able to provide funding for the costs when a limited number of journal articles have to be ordered via their inter-library loan services. When deciding to include quantitative studies only, thus requiring a quantitative synthesis using statistical analysis, these services should be covered in the fees of the postgraduate student, and not have to be paid additionally. Educational institutions requesting postgraduate students to conduct systematic reviews as part of their postgraduate degree should have consultants, librarians, independent reviewers and statisticians skilled in systematic reviews available for the student at no additional cost. Furthermore, suitable supervisor(s) should be identified, based on the supervisor's available time and experience as the supervisor is often expected to assist the student during the search, the appraisal, and data extraction and synthesis processes, which require experience, and can take up considerable time.

The capacity of the student (in terms of cognitive ability, administrative skills and computer literacy skills) and whether the student is willing to take up the often long and lonely process of the systematic review should be considered. Before commencing the review, an interview with the student and the supervisor could be held to address issues of computer literacy, what a systematic review contains, and the advantages and disadvantages of conducting a systematic review. The criteria which are mentioned in Table 2 could also be included. The standards for Initiating a Systematic Review by the Institute of Medicine could be used and considered by the supervisor and/or postgraduate student to obtain an overview of what is expected when initiating a systematic review (Institute of Medicine, 2011). Furthermore, disadvantages and advantages outlined in Table 1 could be discussed. A discussion/interview could be helpful so that the student can 
make an informed decision whether to commmence a systematic review or not. Finally, educational institutions requesting postgraduate students to conduct a systematic review as part of their degree should include the following in their curriculum with regard to research methodology so that students could acquire the competencies needed to conduct a systematic review, an introduction to systematic reviews and meta-analyses, and short learning courses on the steps of the systematic review as well as how to conduct these. We think considering the above-mentioned issues will enhance the quality of both the process of supervision and the review itself.

\section{Conclusion}

This paper has discussed the use of the systematic review in post-graduate nursing education. A systematic review could be a valuable research method to be used by postgraduate nursing students, by which evidence is combined in nontraditional ways, but advantages should be weighed against disadvantages and certain criteria to be able to conduct a systematic review should be considered. This paper could be used to assist the supervisor to use systematic reviews as an appropriate method in postgraduate nursing education method and to identify nursing postgraduate students who will be able to conduct this type of research. By providing information regarding the use of the systematic review in postgraduate nursing education, this paper aimed to enhance the conduct of high-quality systematic reviews by postgraduate nursing education students, which can have a positive impact on patient care.

\section{Acknowledgements}

The authors would like to thank Prof Pamela Hanes for editing the manuscript.

\section{REFERENCES}

Academy of Nutrition and Dietetics. (2012). Evidence analysis manual: Steps in the academy evidence analysis process. Available at: http://www.adaevidencelibrary.com/files/Docs/2012_Jan_ EA_Manual.pdf Accessed 25 April 2014.

Academy of Science in South Africa (ASSAF). (2010). The PhD study: An evidence-based study on how to meet the demands for high-level skills in an emerging economy. Available at: http://www.assaf.co. za/wp-content/uploads/2010/10/40696-Boldesign-PHD-smalloptimised.pdf Accessed 20 June 2015.

Akobeng, A. K. (2005). Understanding systematic reviews and meta-analysis. Archives of Disease in Childhood, 90, 845-848.

Aveyard, H., \& Sharp, P. (2011). A beginner's guide to eudience-based practice in health and social care. Glasgow: McGraw Open Press University.

Bettany-Saltikov, J. (2012). How to do a systematic literature review in nursing. Berkshire: Open University Press.

Bhavsar, A., \& Waddington, H. (2015). 3ie tips for writing strong systematic review applications. Available at: http://www. 3ieimpact.org/en/funding/systematic-reviews-grants/3ie-tipsfor-writing-systematic-review-applications/ Accessed 10 September 2015.

Boland, A., Cherry, M. G., \& Dickson, R. (2008). Doing a systematic review: A student's guide. Philadelphia: SAGE Publications.

Burns, N., \& Grove, S. K. (2013). The practice of nursing Research: Conduct, critique and utilization. St Louis: Elsevier Saunders.

Cantelon, P. L. (2010). National Institute of Nursing Research: Bringing science to life. Available at: http://history.nih.gov/research/ downloads/NINR_History_Book_508.pdf Accessed 8 July 2014.

Centre for Evidence-Based Conservation. (2009). Guidelines for systematic review in conservation and environmental management. Available at: from http://www.cebc.bangor.ac.uk/Documents/ Reviewguidelinesversion3.0_FINALpdf Accessed 14 May 2014.

Centre for Reviews and Dissemination. (2009). Systematic reviews: CRD's guidance for undertaking reviews in health care. York: University of York.

Critical Appraisal Skills Programme. (2006). Evidence-based health care. Oxford: Public Health Resource Unit Accessed 5 March 2015 http://www.phru.nhs.uklcasplcritical_appraisal_tools. htm Accessed 5 March 2015.

Dixon-Woods, M., Bonas, S., Booth, A., Jones, D. A., Miller, T., Sutton, A. J., et al. (2006). How can systematic reviews incorporate qualitative research? A critical perspective. Qualitative Research, 6, 27-44.

Evans, D. (2003). Hierarchy of evidence: a framework for ranking evidence evaluating healthcare interventions. Journal of Clinical Nursing, 12, 77-84.

Evidence for Policy and Practice. (2010). EPPI -Centre methods for conducting systematic reviews. London: the Social Science Research Unit, Institute of Education, University of London.

Frymark, T., Schooling, T., Mullen, R., Wheeler-Hegland, K., Ashford, J., Mccabe, D., et al. (2009). Evidence-based systematic review: oropharyngeal dysphagia behavioural treatments. Part I: background and methodology. Journal of Rehabilitation Research and Development, 46(2), 175-184.

Gough, D., Oliver, S., \& Thomas, J. (2012). An introduction to systematic reviews. London: SAGE Publications.

Hancock, B. (2002). Trent focus for research and development in primary health care an introduction to Qual Res. Nottingham: University of Nottingham.

Harris, M. R. (2005). The librarian's roles in the systematic review process: a case study. Journal of the Medical Library Association, 93(1), 81-87.

Health Care Practice Research and Development Unit. (2005). Evaluation tool for quantitative research studies. Manchester: University of Salford. Available at: http://www.fhsc.salford.ac. uk/hcprdu/quantitative.htm Accessed 13 April 2015.

Hemington, P., \& Brereton, N. (2009). What is a systematic review? Available at: http://www.medicine.ox.ac.uk/bandolier/ painres/download/whatis/syst-review.pdf Accessed 10 September 2015.

Holloway, I., \& Fulbrook, P. (2001). Revisiting qualitative inquiry: Interviewing in nursing and midwifery. Nursing Times Research, 6, 539-550.

Institute of Medicine. (2011). Finding what works in health care standards for systematic reviews. Available at: http://www.iom. edu/ /media/Files/Report\%20Files/2011/Finding-What-Worksin-Health-Care-Standards-for-Systematic-Reviews/Standards \%20for\%20Systematic\%20Review\%202010\%20Insert.pdf Accessed 8 July 2014.

Johanna Briggs Institute. (2011). Reviewers' manual. Available at: http://joannabriggs.org/assets/docs/sumari/ reviewersmanual-2011.pdf Accessed 19 June 2015.

Khan, M. B., Kunz, R., Kleijnen, J., \& Antes, J. (2003). Five steps to conducting a systematic review. Journal of the Royal Society of Medicine, 96, 118-121. 
Kitchenham, B. (2004). Procedures for performing systematic review. Available at: http://www.idi.ntnu.no/emnee/empsc/papers/ kitchenham_2004.pdf Accessed 19 January 2013.

Kung, J., Chiappelli, F., Cajulis, O. O., Avezova, R., Kossan, G., Chew, L., et al. (2010). From systematic reviews to clinical recommendations for evidence-based health care: validation of revised assessment of multiple systematic reviews (RAMSTAR) for grading of clinical relevance. The Open Dentistry Journal, 4, 84-91.

Lam, R. M., \& Kennedy, S. H. (2005). Using meta-analysis to evaluate evidence: practical tips and traps. Canadian J Psychiatry, 50(3), 167-174.

Lincoln, Y. S., \& Guba, E. G. (1985). Naturalistic inquiry. Newbury Park: California Sage.

Louw, G., \& Keller, C. (2006). Undertaking systematic reviews for masters' Dissertations: In the real world professional Arena, when is 'Good' not 'Good Enough'. Thirteenth International Conference on Learning. Montago Bay, Jamaica, 22-25 June.

Mallett, R., Hagen-Zanker, J., Slater, R., \& Duvendack, M. (2012). The benefits and challenges of using systematic reviews in international development research. Journal of Development Effectiveness, 4(3), 445-455.

McGowan, J., \& Sampson, M. (2005). Systematic reviews need systematic searchers. Journal of Medical Library Association, 93(1), 74-80.

Melnyk, B. M. (2004). Integrating levels of evidence into clinical decision making. Pediatric Nursing, 30(4), 323-325.

Melnyk, B., \& Fineout-Overholt, E. (2005). Evidence-based practice in nursing and healthcare: A guide to best practice. Philadelphia: Lippincott, Wiliams \& Wilkins.

Moule, P., \& Goodman, M. (2009). Nursing Research: An Introduction. Singapore: SAGE Publications.

Mouton, J., \& Marais, H. C. (1990). Basic concepts in the methodology of the social sciences. Pretoria: Human Sciences Research Council.

Newhouse, R. P., Dearholt, S. L., Poe, S. S., Pugh, L. C., \& White, K. M. (2007). John Hopkins nursing evidence-based practice: Model and guidelines. Indianapolis: Sigma Theta Tau International.

Olsson, C., Ringnér, A., \& Borglin, G. (2014). Including systematic reviews in $\mathrm{PhD}$ programmes and candidatures in nursing 'Hobson's choice'? Nurse Education in Practice, 14, 102-105.
Petticrew, M., \& Roberts, H. (2006). Systematic reviews in the social sciences: A practical guide. Malden, MA: Blackwell Publishing.

Sackett, D. L., Straus, S., Richardson, S. R., Rosenberg, W., \& Haynes, R. B. (2000). Evidence-based medicine: How to practice and teach EBM. London: Churchill Livingstone.

Sambunjak, D., \& Puljak, L. (2010). Cochrane systematic review as a PhD thesis: an alternative with numerous advantages. Biochemia Medica, 20(3), 319-326.

Scott, N. A., Moga, C., Barton, P., Rashiq, S., Schopflocher, D., Taenzer, P., et al. (2007). Creating clinically relevant knowledge from systematic reviews: the challenges of knowledge translation. Journal of Evaluation in Clinical Practice, 13, 681-688.

Shea, B. J., Grimshaw, J. M., Wells, G. A., Boers, M., Andersson, N., Hamel, C., et al. (2007). A measurement tool for the 'assessment of multiple systematic reviews' (AMSTAR). BMC Medical Research Methodology, 7(10).

Sigma Theta Tau International. (2015). Education. Available at: https:/www.nursingsociety.org/Education/CENE/Pages/ default.aspx Accessed 20 June 2015.

South African Qualifications Authority (SAQA). (2012). The South African qualifications authority: Level descriptors for the South African National qualifications framework. Waterkloof: The South African Qualifications Authority.

The Cochrane Collaboration. (2005). Glossary terms in the Cochrane collaboration. Available at: www.cochrane.org Accessed 10 May 2014.

The Johns Hopkins University School of Nursing. (2015) International network for doctoral education in nursing. Available at: http://nursing.jhu.edu/excellence/inden/ Accessed 20 June 2015.

Thomas, J., \& Harden, A. (2007). Methods for the thematic synthesis of qualitative research in systematic reviews. London: Social Science Research Unit.

Welman, J. C., Kruger, F., \& Mitchell, B. (2012). Research methodology. Cape Town: Oxford University Press.

Whittemore, R., \& Knafl, K. (2005). The integrative review: updated methodology. Journal of Advanced Nursing, 52(5), 546-553. 